\title{
PRZESTRZEŃ POPRZECZNA BRZUCHA - ASPEKTY ANATOMICZNO-KLINICZNE
}

\section{TRANSVERSE ABDOMINAL PLANE - ANATOMICAL AND CLINICAL ASPECTS}

\author{
${ }^{1}$ Zakład Anatomii Prawidłowej i Klinicznej Pomorskiego Uniwersytetu Medycznego w Szczecinie \\ al. Powstańców Wlkp. 72, 71-252 Szczecin \\ Kierownik: dr hab. n. med. Zbigniew Ziętek \\ ${ }^{2}$ Studium Doktoranckie Wydziału Lekarskiego z Oddziałem Nauczania w Języku Angielskim \\ Pomorskiego Uniwersytetu Medycznego w Szczecinie \\ ul. Rybacka 1, 70-204 Szczecin \\ Kierownik: prof. dr hab. n. med. Maria Chosia \\ ${ }^{3}$ Klinika Chirurgii Ogólnej i Gastroenterologicznej Pomorskiego Uniwersytetu Medycznego w Szczecinie \\ ul. Unii Lubelskiej 1, 71-252 Szczecin \\ Kierownik: dr hab. n. med., prof. PUM Marek Kamiński
}

\section{Summary}

In medicine spectacular progress can be observed at many stages, which sometimes requires the redefinition of already known anatomical structures. One of them is the transverse abdominal plane, which was the focus of anaesthetists.

It was observed that anaesthetics introduced locally into this plane have similar power to a traditional epidural procedure or spinal anaesthesia. The concept of the transverse abdominal plane is a relatively new anatomical term which was introduced into clinical medicine by anaesthetists. Because of the potential performance of anaesthetic procedures through access to the transverse abdominal plane, there has been a growing interest not only expressed by anaesthetists, but also anatomists who wish to explore new anatomical aspects of this plane. It is generally believed that anatomical studies will provide more information on this plane, which can contribute to a wider spread of this procedure among anaesthetists.

K e y w ord s: transverse abdominal plane - lumbar triangle - analgesia.

\section{Streszczenie}

Postęp w medycynie nieraz wymusza przedefiniowanie znanych już struktur anatomicznych. Jedną z takich struktur jest przestrzeń poprzeczna brzucha (transversus abdominis plane). Zaobserwowano, że wprowadzony do niej środek miejscowo znieczulający działa silnie jak tradycyjnie wykonywane procedury, takie jak znieczulenie zewnątrzoponowe i podpajęczynówkowe.

Pojęcie przestrzeni poprzecznej brzucha jest stosunkowo nowym terminem anatomicznym, wprowadzonym do medycyny klinicznej przez lekarzy anestezjologów. W związku z możliwością wykonywania procedur anestezjologicznych poprzez dostęp do przestrzeni poprzecznej brzucha obserwuje się rosnące zainteresowanie tą strukturą nie tylko wśród lekarzy anestezjologów, ale także anatomów. Badania anatomiczne pozwolą lepiej poznać przestrzeń poprzeczną brzucha, co może przyczynić się do rozpropagowania wśród lekarzy anestezjologów nowej formy znieczulenia.

H a s $¥$ a: przestrzeń poprzeczna brzucha - trójkąt lędźwiowy - analgezja.

\section{Wstęp}

Niepodważalny jest fakt, że podstawą wszelkich procedur diagnostyczno-terapeutycznych jest dokładne poznanie budowy anatomicznej ludzkiego ciała. Wbrew powszechnie panującemu poglądowi wiedza na temat budowy anatomicznej ludzkiego ciała nie jest zamkniętym rozdziałem. Odkrywanie nowych struktur anatomicznych i nowych stosunków anatomiczno-topograficznych w świetle oczekiwań 
współczesnej medycyny jest ciągłym wyzwaniem dla anatomii prawidłowej człowieka i bodźcem do jeszcze intensywniejszego rozwoju.

\section{Przestrzeń poprzeczna brzucha}

W 2001 r. opisano innowacyjną metodę zapewniającą analgezję w obrębię otrzewnej ściennej, mięśni oraz skóry przedniej ściany jamy brzusznej [1]. Polega ona na podaniu środka miejscowo znieczulającego do przedziału określanego jako przestrzeń poprzeczna brzucha (transversus abdominis plane - TAP). Procedura ta zastępuje tradycyjne formy znieczulenia, takie jak znieczulenie zewnątrzoponowe i znieczulenie podpajęczynówkowe, wymagane w operacjach w obrębie przedniej ściany brzucha, na narządach miednicy mniejszej czy w operacjach urologicznych, np. na mosznie. Pomimo udokumentowanego bezpieczeństwa oraz oczywistych korzyści metoda ta nie jest powszechna w praktyce anestezjologicznej. Ten stan rzeczy może wynikać przede wszystkim z ograniczenia badań anatomicznych nad przestrzenią poprzeczną brzucha, które mogłyby przyczynić się do pełniejszego i wyczerpującego zrozumienia jej anatomii [2].

Wyodrębnienie przestrzeni poprzecznej brzucha jest nową próbą podziału topograficznego istniejących i znanych już struktur anatomicznych. Przestrzeń poprzeczna brzucha sytuuje się w obrębie ściany jamy brzusznej; jest strukturą parzystą, posiadającą wyraźnie istniejące anatomiczne granice i określoną zawartość.

Powłoki jamy brzusznej, określane również jako ściana jamy brzusznej, rozciągają się od łuku żebrowego i wyrostka mieczykowatego ku górze, ku dołowi do więzadła pachwinowego i kości miednicy, bocznie i ku tyłowi od powięzi piersiowo-lędźwiowej, przyśrodkowo zaś do kresy białej [3]. Warstwy tworzące powłoki jamy brzusznej, począwszy od struktur położonych najbardziej powierzchownie do struktur najgłębszych, to: skóra, powięź powierzchowna, tkanka tłuszczowa, mięśnie grupy przedniej, bocznej i tylnej, powięź poprzeczna oraz otrzewna ścienna. Mięśnie wraz z ich rozcięgnami wchodzące w skład ściany jamy brzusznej ułożone są nachodzącymi na siebie warstwami. Ułożone są w trzy grupy, wśród których wyróżnia się grupę przednią obejmującą $\mathrm{m}$. prosty brzucha i m. piramidowy, grupę boczną, w skład której wchodzą m. skośny brzucha zewnętrzny i wewnętrzny oraz $\mathrm{m}$. poprzeczny brzucha, a także ostatnią grupę tylną z m. czworobocznym lędźwi. Każda warstwa mięśniowa otoczona jest tkanką łączną zwaną omięsną zewnętrzną, która jest jednocześnie strukturą demarkacyjną poszczególnych kompartymentów występujących w obrębie ściany brzucha, wśród których jedną z nich jest tzw. przestrzeń poprzeczna brzucha.

Unerwienie ściany jamy brzusznej zaopatrywane jest przez gałęzie czuciowe nerwów odcinka Th7-L4 rdzenia kręgowego. Unaczynienie pochodzi od gałęzi tętnicy biodrowej zewnętrznej: t. nabrzusznej dolnej i okalającej biodro głębokiej oraz t. piersiowej wewnętrznej i jej gałęzi nabrzusznej górnej oraz mięśniowo-przeponowej.

Przestrzeń poprzeczna brzucha jest anatomicznym przedziałem przyjmującym trójkątny kształt, utworzonym przez dwa mięśnie, m. skośny brzucha wewnętrzny oraz m. poprzeczny brzucha. Obejmuje ścianę jamy brzusznej w miejscu, gdzie wspomniane dwa mięśnie występują. Ku przodowi ograniczona jest przez kresę półksiężycowatą, tzw. kresę Spiegela, będącą rozcięgnem mięśni skośnych brzucha zewnętrznego, wewnętrznego oraz poprzecznego brzucha. Przestrzeń ta rozciąga się od chrząstki IX żebra do guzka łonowego [4]. Górne ograniczenie przestrzeni poprzecznej brzucha stanowi brzeg podżebrowy i dalej przebiega wzdłuż brzegu m. najszerszego grzbietu. Podstawę trójkątnej przestrzeni poprzecznej brzucha stanowi więzadło pachwinowe, grzebień kości biodrowej oraz tylne ramię trójkąta lędźwiowego, określanego mianem trójkąta Petita.

Zawartość przestrzeni poprzecznej brzucha obejmuje naczynia krwionośne oraz pnie nerwowe wraz z ich gałęziami. W jej obrębie przebiegają następujące nerwy: międzyżebrowe, podżebrowy oraz gałęzie splotu lędźwiowego jak n. biodrowo-podbrzuszny, n. biodrowo-pachwinowy oraz inne gałęzie pochodzące z segmentów Th6-L1 rdzenia kręgowego.

Nerwy odcinka rdzenia kręgowego Th6-Th9 wchodzą w obszar określany jako przestrzeń poprzeczna brzucha, wychodząc spod łuku żebrowego w obszarze zawartym pomiędzy linią pośrodkową a linią pachową przednią. W rzucie linii pachowej przedniej w obszarze przestrzeni poprzecznej brzucha wiele gałęzi nerwowych pochodzi od nerwów rdzeniowych odcinka rdzenia kręgowego Th9-L1, podążających wzdłuż tętnicy okalającej biodro głębokiej, dochodzących do granicy przedniej przestrzeni tzw. kresy półksiężycowatej. Grupa tych wszystkich nerwów znajdujących się w przestrzeni poprzecznej brzucha otrzymała nazwę splotu przestrzeni poprzecznej brzucha (TAP-plexus) [5]. Jest to kolejny przykład przedefiniowania istniejących struktur anatomicznych, które nie są pojęciami określającymi istniejące struktury anatomiczno-morfologiczne, jak np. splot lędźwiowy czy ramienny, ale strukturami stworzonymi na użytek tzw. anatomii czynnościowej [4]. Użycie terminu splotu wiąże się z istnieniem bogatych połączeń pomiędzy poszczególnymi gałęziami nerwów znajdujących się w przestrzeni poprzecznej brzucha, szczególnie na poziomie wspomnianej tętnicy okalającej biodro głębokiej. Zaobserwowano charakterystyczną sytuację polegającą na tym, że mniejsze włókna nerwowe opuszczają podążające przyśrodkowo i ku dołowi główne pnie, zaopatrując przylegające struktury anatomiczne [5].

W badaniach anatomicznych i morfologicznych TAP posługiwano się różnymi technikami. Dotyczyły one zarówno badań na zwłokach, jak i na żywych osobnikach, obejmując m.in. bezpośrednie badania sekcyjne mające na celu określenie granic oraz zawartości przestrzeni poprzecznej brzucha [5, 6], a także analizy tomografii komputerowej z podaniem środków kontrastowych $[6,7,8]$ lub samego barwnika z następową analizą zasięgu penetracji 
przestrzeni przez podany barwnik, z jednoczesnym określeniem struktur zanurzonych w podanym barwniku [5].

Należy podkreślić, że prace dotyczące zdefiniowania anatomicznego przestrzeni poprzecznej brzucha są nieliczne i niekompletne. Pozostaje wiele nierozwiązanych kwestii, jak np. najlepszy dostęp do przestrzeni oraz określenie stałych punktów, które pozwalałyby na bezpieczne i skuteczne wykonywanie blokad pęczków nerwowych. Optymistyczne wydaje się, że zainteresowaniu anestezjologów i chirurgów przestrzenią poprzeczną brzucha towarzyszą próby dokładniejszej eksploracji z użyciem innych metod badawczych, jak USG czy tomografii komputerowej [9, 10]. Wstępne wyniki dotyczące morfologii TAP określanej radiologicznie i z użyciem barwników okazały się zbieżne z dotychczasowymi rozważaniami anatomicznymi $[3,6]$.

\section{Trójkąt lędźwiowy - trójkąt Petita}

W badaniach przestrzeni poprzecznej brzucha podkreśla się aspekt bezpiecznego nakłucia poprzez naturalne anatomiczne wrota. Jednym $\mathrm{z}$ nich wydaje się trójkąt lędźwiowy, zwany trójkątem Petita. Dotychczasowy opis anatomii trójkąta lędźwiowego wydaję się być niekompletny i mało przydatny dla anestezjologów czy lekarzy innych specjalności chcących wykonywać blokady pęczków nerwowych przestrzeni poprzecznej brzucha. Dlatego istnieje konieczność uaktualnienia i dostosowania opisów trójkąta lędźwiowego do potrzeb klinicznych $[3,6]$.

Dostęp do przestrzeni poprzecznej brzucha możliwy jest z wykorzystaniem dwóch technik różniących się stopniem trudności, efektywnością i obecnością powikłań [11, 12]. Klasyczna technika znieczulenia, opisana przez Rafiego, wykorzystuje jako punkt dostępu do przestrzeni poprzecznej brzucha trójkąt lędźwiowy Petita [1]. Anatomicznie trójkąt lędźwiowy jest przedstawiany jako trójkąt ostrokątny, którego podstawa skierowana jest ku dołowi, opierając się o grzebień kości biodrowej, natomiast wierzchołek skierowany ku górze, w kierunku kąta dolnego łopatki. Ramiona trójkąta stanowią odpowiednio: tylny brzeg m. skośnego zewnętrznego brzucha jako ramię boczne, zaś przedni brzeg mięśnia najszerszego grzbietu jako ramię przyśrodkowe trójkąta. Dno trójkąta lędźwiowego stanowi m. skośny brzucha wewnętrzny.

W praktyce klinicznej metoda klasyczna przedstawia się następująco: najpierw wyznacza się palpacyjnie przyśrodkowe ramię trójkąta lędźwiowego, tj. przedni brzeg m. najszerszego grzbietu w miejscu jego przyczepu do wargi zewnętrznej grzebienia biodrowego. Po zidentyfikowaniu miejsca wprowadza się igłę z ostrzem posiadającym specjalny ruchomy mechanizm zabezpieczający, nachodzący na ostrze igły; z chwilą, gdy końcówka ostrza znajdzie się w jakiejś wolnej przestrzeni, następuje gwałtowne odblokowanie mechanizmu zabezpieczającego ostrą końcówkę igły. Temu ruchowi towarzyszy słyszalne charakterystyczne kliknięcie (pop sensation). Igłę należy ostrożnie wprowadzać, prostopadle do skóry powyżej grzebienia biodrowego, do momentu usłyszenia charakterystycznego kliknięcia, które świadczy o prawidłowym położeniu igły pomiędzy m. skośnym brzucha wewnętrznym a poprzecznym, czyli w poszukiwanej przez wykonującego procedurę przestrzeni poprzecznej brzucha. Następnie po wykonaniu testu aspiracji podaje się środek miejscowo znieczulający.

W późniejszym okresie klasyczna metoda Rafiego została zmodyfikowana przez McDonnela $i$ wsp., którzy zalecali wprowadzenie igły prostopadle do skóry tuż nad grzebieniem biodrowym [13]. Penetrując igłą struktury powięziowe m. skośnego brzucha zewnętrznego i m. skośnego brzucha wewnętrznego, słyszy się charakterystyczne dwa kliknięcia, przy czym pierwsze kliknięcie odpowiada przestrzeni pomiędzy m. skośnym brzucha zewnętrznym a wewnętrznym, natomiast drugie oznacza umiejscowienie igły pomiędzy m. skośnym brzucha wewnętrznym i m. poprzecznym brzucha, a więc we właściwej przestrzeni poprzecznej brzucha [13].

Skuteczność nakłucia przestrzeni poprzecznej brzucha w obu metodach była mała, co wiązało się z sugerowaną przez wielu autorów nie do końca poznaną zmiennością trójkąta lędźwiowego [6, 14]. Spostrzeżenia autorów na temat niskiej skuteczności analgezji drogą punkcji przestrzeni poprzecznej brzucha opierają się nie tylko na intuicji, ale także na nielicznych opracowaniach topografii trójkąta, jego zmienności oraz adoptowania schematów nakłuć tego trójkąta do celów analgezji przedniej ściany brzucha.

Istnieje pilna konieczność dokładniejszej eksploracji trójkąta lędźwiowego, opracowania jego morfologii i topografii w celu doprecyzowania klasycznej metody punkcji przestrzeni poprzecznej brzucha. Postulował to nawet sam autor metody klasycznej blokady przestrzeni poprzecznej brzucha, uważając, że liczne modyfikacje jego metody, które nie zawsze są słuszne i korzystne dla pacjentów, wynikają z braku dokładnych opracowań topograficznych tej przestrzeni oraz trójkąta lędźwiowego [15].

Wprowadzenie do anestezji miejscowej metod obrazowania ultrasonograficznego umożliwiło w miarę prosty i szybki sposób na identyfikację TAP i możliwość nakłucia jej w każdym miejscu, jednakże wydaję się, że nakłucie poprzez trójkąt lędźwiowy może być najbardziej bezpieczne dla chorego [16].

\section{Podsumowanie}

Użycie w praktyce klinicznej przestrzeni poprzecznej brzucha znalazło uznanie przede wszystkim w środowisku anestezjologicznym oraz chirurgicznym, gdyż blokada nerwowa wykonana w jej obrębie zapewnia zadowalająca analgezję pooperacyjną w zakresie przedniej ściany jamy brzusznej, szczególnie w obszarach obejmujących dolne partie.

$\mathrm{Z}$ powodzeniem stosowano blokadę przestrzeni poprzecznej brzucha, tzw. TAP blok, u pacjentów poddanych m.in. operacjom przepukliny pachwinowej, resekcji jelita grubego, appendektomii, cięciu cesarskiemu, histerektomii 
brzusznej, radykalnej prostatektomii [13, 16, 17, 18], jak również transplantacji nerek, limfadenektomii pachwinowej, zabiegom plastycznym oraz rekonstrukcyjnym w obrębie przedniej ściany jamy brzusznej [18].

Badania przestrzeni poprzecznej brzucha dostarczyły również dokładnych informacji dotyczących unerwienia przedniej ściany jamy brzusznej [3], co w konsekwencji pozwoliło na ograniczenie wielu powikłań $[8,14]$. Dokładne zbadanie i zrozumienie anatomii tego obszaru staje się niezbędne, aby można było w sposób bezpieczny i korzystny dla pacjenta dokonywać procedur chirurgiczno-anestezjologicznych.

\section{Piśmiennictwo}

1. Rafi A.N.: Abdominal field block: A new approach via the lumbar triangle. Anaesthesia. 2001, 56, 1024-1026.

2. Young M.J., Gorlin A.W., Modest V.E., Quraishi S.A.: Clinical implications of the transversus abdominis plane block in adults. Anesthesiol Res Pract. 2012, doi:10.1155/2012/731645.

3. Klaassen Z., Marshall E., Tubbs R.S., Louis R.G. Jr., Wartmann C.T., Loukas M.: Anatomy of the ilioinguinal and iliohypogastric nerves with observations of their spinal nerve contributions. Clin Anat. 2011, 24, 454-461.

4. Rozen W.M., Tran T.M., Ashton M.W., Barrington M.J., Ivanusic J.J., Taylor G.I.: Refining the course of the thoracolumbar nerves: a new understanding of the innervation of the anterior abdominal wall. Clin Anat. 2008, 21 (4), 325-333.

5. Tran T.M., Ivanusic J.J., Hebbard P., Barrington M.J.: Determination of spread of injectate after ultrasound-guided transversus abdominis plane block: a cadaveric study. Br J Anaesth. 2009, 102, 123-127.

6. Jankovic Z.B., du Feu F.M., Mc Connell P.: An anatomical study of the transversus abdominis plane block: location of the lumbar triangle of Petit and adjacent nerves. Anesth Analg. 2009, 109, 981-985.
7. Parkih B.K., Waghmare V.T., Shah V.R., Mehta T., Butala B.P., Parkih G.P. et al:: The analgesic efficacy of ultrasound-guided transversus abdominis plane block for retroperitoneoscopic donor nephrectomy: A randomized controlled study. Saudi J Anaesth. 2013, 7, 43-47.

8. Jankovic Z., Ahmad N., Ravishankar N., Archer F.: Transversus abdominis plane block: How safe is it? Anaesth Analg. 2008, 107, 1758-1759.

9. Hebbard P., Fujiwara Y., Shibata Y., Royse C.: Ultrasound-guided transversus abdominis plane (TAP) block. Anaesth Intensive Care. 2007, 35, 616-617.

10. Hebbard P.: Subcostal transversus abdominis plane block under ultrasound guidance. Anesth Analg. 2008, 106, 674-675.

11. McDonnell J.G., O'Donnell B.D., Curley G., Heffernan A., Power C., Laffey J.G.: The analgesic efficacy of transversus abdominis plane block after caesarean delivery: A randomized controlled trial. Anesth Analg. 2008, 106, 186-119.

12. Carney J., McDonnell J.G., Ochana A., Bhinder R., Laffey J.G.: The transversus abdominis plane block provides effective postoperative analgesia in patients undergoing total abdominal hysterectomy. Anesth Analg. 2008, 107, 2056-2060.

13. McDonnell J.G., O'Donnell B.D., Curley G., Heffernan A., Power C., Laffey J.G.: The analgesic efficacy of TAP block after abdominal surgery: A prospective randomized controlled trial. Anesth Analg. 2007, 104, 193-197.

14. Jankovic Z:: Transversus abdominis plane block: The holy grail of anaesthesia for (lower) abdominal surgery. Periodicum Biologorum. 2009, 111, 203-208.

15. Rafi A.N.: Abdominal field block via the lumbar triangle revisited Anaesthesia. 2012, 67, 1399-1401.

16. O'Donnell B.D., McDonnell J.G., McShane A.J.: Letter to the Editor. The transversus abdominis plane (TAP) block in open retropubic prostatectomy. Reg Anesth Pain Med. 2006, 31, 91.

17. Mukhtar K., Khattak I.: Transversus abdominis plane block for laparoscopic surgery. Br J Anaesth. 2009, 102, 143-144.

18. French J.L., McCullough J., Bachra P., Bedforth N.M.: Transversus abdominis plane block for analgesia after Caesarean section in a patient with an intracranial lesion. Int J Obstet Anesth. 2009, 8, 52-54. 